\title{
Anti-atherogenic effect of Humulus japonicus in apolipoprotein E-deficient mice
}

\author{
HAIAN LIM ${ }^{1,2^{*}}$, JUNG-RAN NOH ${ }^{1 *}$, YONG-HOON KIM ${ }^{1,3}$, JUNG HWAN HWANG $^{1}$, KYOUNG-SHIM KIM $^{1,3}$, \\ DONG-HEE CHOI ${ }^{1}$, MIN-JEONG GO ${ }^{1}$, SANG-SEOP HAN ${ }^{2}$, WON-KEUN OH ${ }^{4}$ and CHUL-HO LEE ${ }^{1,3}$ \\ ${ }^{1}$ Laboratory Animal Resource Center, Korea Research Institute of Bioscience and Biotechnology (KRIBB), Daejeon 34141; \\ ${ }^{2}$ Department of Toxicology Evaluation, Konyang University, Daejeon 35365; ${ }^{3}$ Department of Functional Genomics, \\ University of Science and Technology (UST), Daejeon 34113; ${ }^{4}$ Korea Bioactive Natural Material Bank, Research Institute \\ of Pharmaceutical Sciences, College of Pharmacy, Seoul National University, Seoul 08826, Republic of Korea
}

Received June 29, 2015; Accepted August 12, 2016

DOI: $10.3892 /$ ijmm.2016.2727

\begin{abstract}
Humulus japonicus (HJ) is used as a traditional medicine in Korea owing to its multiple properties including anti-mycobacterial, antioxidant and antihypertensive effects. The present study aimed to examine the anti-inflammatory and anti-atherogenic effects of a methanol extract of HJ. In lipopolysaccharide-stimulated RAW 264.7 cells, HJ significantly suppressed the mRNA expression and secretion of pro-inflammatory cytokines [tumor necrosis factor- $\alpha$, interleukin (IL) $-1 \beta$ and IL-6)], and the release of inflammatory mediators such as nitrite and prostaglandin $\mathrm{E}_{2}$, together with a concomitant decrease in the mRNA levels of inducible nitric oxide synthase and cyclooxygenase-2. To examine whether $\mathrm{HJ}$ is capable of inhibiting experimental atherogenesis in an animal model, we randomly divided apolipoprotein E-deficient $\left(\operatorname{apoE}^{-/}\right)$mice into three groups: mice fed an atherogenic diet plus vehicle ( $0.5 \%$ carboxymethyl cellulose) as the control vehicle group, and mice fed an atherogenic diet plus either 100 (HJ100) or $500 \mathrm{mg} / \mathrm{kg}$ (HJ500) of HJ as the experimental groups. After 12 weeks of $\mathrm{HJ}$ administration, lipid accumulation and the formation of atherosclerotic lesions in the aorta (en face) and the aortic sinus markedly decreased in the HJ500 group compared with the corresponding values in the vehicle control
\end{abstract}

Correspondence to: Dr Chul-Ho Lee, Laboratory Animal Resource Center, Korea Research Institute of Bioscience and Biotechnology (KRIBB), 125 Gwahak-ro, Yuseong-gu, Daejeon 34141, Republic of Korea

E-mail: chullee@kribb.re.kr

*Contributed equally

Abbreviations: VCAM-1, vascular cell adhesion molecule-1; ICAM-1, intercellular adhesion molecule-1; iNOS, inducible nitric oxide synthase; COX-2, cyclooxygenase-2; MCP-1, monocyte chemoattractant protein-1; TNF- $\alpha$, tumor necrosis factor- $\alpha$; IL-1 $\beta$, interleukin-1 $\beta$; IL-6, interleukin-6; IL-18, interleukin-18

Key words: Humulus japonicus, atherosclerosis, inflammation, cytokines, apolipoprotein E-deficient mice group. Moreover, monocyte and macrophage infiltration in the aortic sinus was markedly reduced in the HJ500 group. Reverse transcription-quantitative polymerase chain reaction analysis of the whole aorta showed that the mRNA levels of intercellular adhesion molecule-1, monocyte chemoattractant protein-1, CD68 and IL-18 were significantly decreased in the HJ500 group. Collectively, these findings suggest that HJ may suppress atherosclerosis by inhibiting lipid accumulation and the expression of pro-atherogenic factors, and it may be effective at preventing the development of atherosclerosis.

\section{Introduction}

Recent statistics from the World Health Organization indicate that almost 17.5 million people died from cardiovascular disease (CVD) in 2012, which represents nearly $31 \%$ of deaths worldwide (1). Of these deaths, an estimated 7.4 million were due to coronary heart disease and 6.7 million were due to stroke (1). The principal cause of heart disease, including myocardial infarction and stroke, in Western society is atherosclerosis, a chronic inflammatory disease characterized by cholesterol and lipid accumulation within the arterial wall (2). Atherosclerotic cardiovascular disease (ACD) is affected by several factors including age, gender, genetic predisposition, smoking, stress and dietary habits (3-5). However, despite lifestyle modifications and the development of novel pharmacological therapies to lower the concentrations of plasma cholesterol, ACD remains the principal cause of death worldwide $(1,6,7)$.

Atherosclerosis is not only a lipid disorder but also a chronic inflammatory disease affecting the arterial vessel wall $(4,8,9)$. The first step in the pathogenesis of atherosclerosis is triggered by the deposition of low-density lipoprotein (LDL) cholesterol in the arterial endothelium. The deposited LDL is modified to oxidized LDL (oxLDL), which stimulates the endothelial cells to express adhesion molecules [vascular cell adhesion molecule-1 (VCAM-1) and intercellular adhesion molecule-1 (ICAM-1)] and chemokines [monocyte chemoattractant protein-1 (MCP-1) and interleukin (IL)-8] $(10,11)$. During this process, the overexpression of adhesion molecules leads to the recruitment of monocytes in the arterial endothelium, which eventually migrate into the intima and 
differentiate into pro-atherogenic macrophages. The proatherogenic macrophages are activated by residual oxLDL, endotoxins, and heat-shock proteins, and release inflammatory cytokines and growth factors, thus resulting in endothelial activation. This leads to the induction of an inflammatory response through the increased recruitment of leukocytes and the proliferation of smooth muscle cells (12), which release various inflammatory cytokines, such as tumor necrosis factor- $\alpha$ (TNF- $\alpha$ ), IL- $1 \beta$ and IL- 6 , consequently leading to the accumulation of lipid-laden foam cells and the development of atherosclerosis $(4,13,14)$.

Humulus japonicus $(\mathrm{HJ})$ of the family Cannabaceae, is an annual climbing vine originating from East Asia, including Korea and China (15). It is wind-pollinated and has a flowering stage that lasts from August to October. This plant grows rapidly as a vine that forms dense stands and displaces native vegetation by outcompeting them for essential resources. It may pose a threat to the environment when invading riparian habitats. It has been demonstrated that the pollen of this plant is allergenic, and is considered as one of the major causes of pollen allergy (16). To date, $\mathrm{HJ}$ has been reported to exert anti-mutagenic (17), antimicrobial (18), antioxidant $(18,19)$, anticancer (19), anti-mycobacterial (20), and anti-inflammatory (21) effects. From the results of previous studies, we speculated that the antioxidant and anti-inflammatory effects of HJ may also contribute to the anti-atherosclerotic effect of HJ. Using RAW 264.7 cells, a murine macrophage cell line, and apolipoprotein E-deficient $\left(\mathrm{apoE}^{-/}\right)$mice fed an atherogenic diet, a well-known animal model of atherosclerosis, we performed the present study in order to examine the anti-inflammatory and anti-atherogenic effects of $\mathrm{HJ}$.

\section{Materials and methods}

Preparation of HJ extract. HJ was purchased from Gangwon Herbs (Wonju, Korea) in July, 2014. The voucher specimen was identified by Professor W.-K. Oh, and a voucher specimen (SNU-2014-0004) was deposited at the College of Pharmacy, Seoul National University, Seoul, Korea. Then, the HJ extract was prepared and supplied by the Korea Bioactive Natural Material Bank (Seoul, Korea). Briefly, the dried aerial parts of HJ were soaked in $100 \%$ methanol in an extraction container for 2 days at room temperature. The methanol-soluble extract was then filtered through cheesecloth, concentrated exhaustively, and dried under reduced pressure to afford a methanol extract. This HJ extract was suspended in $0.5 \%$ carboxymethyl cellulose (CMC) at a concentration of $50 \mathrm{mg} / \mathrm{ml}$ as a stock solution, and the working solution of $\mathrm{HJ}$ was adjusted to the intended concentrations for use in the in vitro and in vivo experiments in the present study.

Cell culture and HJ treatment. The RAW 264.7 cells, a murine macrophage cell line, were purchased from the American Type Cell Culture (ATCC; Manassas, VA, USA), cultured in Dulbecco's modified Eagle's medium (DMEM) containing $10 \%$ fetal bovine serum (FBS) and $1 \%$ penicillin/streptomycin antibiotics (Gibco, Carlsbad, CA, USA), and maintained at $37^{\circ} \mathrm{C}$ in a humidified $5 \% \mathrm{CO}_{2}$ incubator. The cells were seeded in 12 -well plates $\left(1 \times 10^{5}\right.$ cells/well), incubated overnight, and thereafter, co-treated with different concentrations of $\mathrm{HJ}$
(200 and $400 \mu \mathrm{g} / \mathrm{ml}$ ) and lipopolysaccharide (LPS; $1 \mu \mathrm{g} / \mathrm{ml}$; Sigma-Aldrich, St. Louis, MO, USA) for $24 \mathrm{~h}$. The doses of HJ were determined by preliminary tests using various concentrations $(50-500 \mu \mathrm{g} / \mathrm{ml})$ without cell toxicity to examine the anti-inflammatory effect.

Measurement of inflammation-related gene expression in LPS-stimulated RAW 264.7 cells by reverse transcription-quantitative polymerase chain reaction $(R T-q P C R)$. The RAW 264.7 cells were treated with $\mathrm{HJ}$ extract for $1 \mathrm{~h}$, and then stimulated with LPS or vehicle for $24 \mathrm{~h}$. The total RNA from the cells was extracted and the samples were reverse transcribed using the iScript cDNA synthesis kit (BioRad, Hercules, CA, USA). The resulting cDNA was amplified using the Exicycler 96 quantitative Real-Time PCR system and SYBR Premix Ex Taq (both from Bioneer, Daejeon, Korea) according to the manufacturer's instructions. Oligonucleotide primers [for TNF- $\alpha$, IL-1 $\beta$, IL-6, cyclooxygenase-2 (COX-2) and inducible nitric oxide synthase (iNOS)] were designed by Primer Express 3.0 software (Applied BioSystems, Carlsbad, CA, USA); the primer sequences used in the experiments are listed in Table I. The cycling conditions were $95^{\circ} \mathrm{C}$ for $10 \mathrm{~min}$, followed by 40 cycles of $95^{\circ} \mathrm{C}$ for $10 \mathrm{sec}$, and $60^{\circ} \mathrm{C}$ for $1 \mathrm{~min}$. To detect and remove possible primer-dimer artifacts, a dissociation curve was generated for the following cycling conditions: $95^{\circ} \mathrm{C}$ for $15 \mathrm{sec}, 60^{\circ} \mathrm{C}$ for $1 \mathrm{~min}$, and $95^{\circ} \mathrm{C}$ for $15 \mathrm{sec}$. The results were normalized to $18 \mathrm{~s}$ mRNA levels (reference gene).

Determination of pro-inflammatory cytokine secretion in LPS-stimulated RAW 264.7 cells. The secretion levels of TNF- $\alpha$, IL-1- $\beta$ and IL- 6 were determined using culture supernatants from the LPS-stimulated RAW 264.7 cells by capture ELISA using Nunc-Immuno ${ }^{\mathrm{TM}}$ Microwell 96-well MaxiSorp ${ }^{\mathrm{TM}}$ microplates (Nunc A/S, Roskilde, Denmark). Pro-inflammatory cytokine levels were measured according to the manufacturer's instructions using the Mouse ELISA kit, BD OptEIA ${ }^{\mathrm{TM}}$ (Pharmingen, San Diego, CA, USA). Briefly, the 96-well plates were coated overnight at $4^{\circ} \mathrm{C}$ with a capture antibody (antimouse TNF- $\alpha$, IL-1 $\beta$ and IL-6) in coating buffer (1:250). After the plates were washed with washing buffer $[0.05 \%$ Tween-20 in 1X phosphate-buffered saline (PBS)], the plates were blocked with assay diluent (10\% FBS in $1 \mathrm{X}$ PBS) for $1 \mathrm{~h}$ at room temperature. After the plates were washed, standards and samples were added to the wells and incubated for $2 \mathrm{~h}$ at room temperature. After the plates were washed, working detector (biotinylated anti-mouse cytokine and streptavidin-horseradish peroxidase conjugate in assay diluent) were added and incubated for $1 \mathrm{~h}$ at room temperature. The wells were again washed and the substrate solution (tetramethylbenzidine and hydrogen peroxide) was added and incubated for $30 \mathrm{~min}$ at room temperature in the dark. After 30 min, stop solution $\left(1 \mathrm{~N} \mathrm{H}_{2} \mathrm{SO}_{4}\right)$ was added. The absorbance was measured using a microplate reader (Thermo Multiskan Spectrum, Thermo Fisher Scientific, Waltham, MA, USA) at $450 \mathrm{~nm}$. A standard curve was obtained using serial dilutions starting from 0 upto $1,000 \mathrm{pg} / \mathrm{ml}$.

Assessment of nitrite and prostaglandin $E_{2}\left(P G E_{2}\right)$ production in LPS-stimulated RAW 264.7 cells. The RAW 264.7 cells were plated in a 12 -well plate as mentioned above, and the concentration of nitrite was measured using Griess reagent. 
Table I. Primer sequences for RT-qPCR of target genes.

Gene Primer sequence (5'-3')

18s F: 5'-GACACGGACAGGATTGACAGATTGATAG-3' R: 5'-GTTAGCATGCCAGAGTCTCGTTCGTT-3'

VCAM-1 F: 5'-ACTGTTTATTACAGCCCCGC-3' R: 5'-ACTTCAACGATGGGGACTTG-3'

ICAM-1 F: 5'-GTCGAAGGTGGTTCTTCTGAGC-3' R: 5'-TCCGTCTGCAGGTCATCTTAGG-3'

iNOS F: 5'-GTTCTCAGCCCAACAATACAAGA-3' R: 5'-GTGGACGGGTCGATGTCAC-3'

COX-2 F: 5'-GGGTGTCCCTTCACTTCTTTCA-3' R:5'-GAGTGGGAGGCACTTGCATT-3'

MCP-1 F: 5'-CAGCAAGATGATCCCAATGAGTAG-3' R: 5'-TCTCTTGAGCTTGGTGACAAAAAC-3'

CD68 F: 5'-TCACAGTTCACACCAGCTCC-3' R: 5'-TCACAGTTCACACCAGCTCC-3'

TNF- $\alpha \quad$ F: 5'-TGGCCTCCCTCTCATCAGTT-3' R: 5' - CCTCCACTTGGTGGTTTGCT-3'

IL-1 F: 5'-CTACAGGCTCCGAGATGAACAAC-3' R: 5'-TCCATTGAGGTGGAGAGCTTTC-3'

IL-6 F: 5'-GTTGCCTTCTTGGGACTGATG-3' R: 5'-GGGAGTGGTATCCTCTGTGAAGTCT-3'

IL-18 F: 5'-GGCTGCCATGTCAGAAGACT-3' R: 5'-GTCTGGTCTGGGGTTCACTG-3'

F, forward; R, reverse; VCAM-1, vascular cell adhesion molecule-1; ICAM-1, intercellular adhesion molecule-1; iNOS, inducible nitric oxide synthase; COX-2, cyclooxygenase-2; MCP-1, monocyte chemoattractant protein-1; TNF- $\alpha$, tumor necrosis factor- $\alpha$; IL-1 $\beta$, interleukin- $1 \beta$; IL-6, interleukin-6; IL-18, interleukin-18.

The culture supernatant $(100 \mu \mathrm{l})$ was mixed with Griess reagent $(100 \mu \mathrm{l})$ [equal volumes of $1 \%(\mathrm{w} / \mathrm{v})$ sulfanilamide in $5 \%(\mathrm{v} / \mathrm{v})$ phosphoric acid and $0.1 \%(\mathrm{w} / \mathrm{v})$ naphthyl ethylenediamine dihydrochloride], and incubated at room temperature for $15 \mathrm{~min}$. The light absorbance of the mixture was read at $540 \mathrm{~nm}$ using a microplate reader. The concentration of nitrite was calculated from a serial dilution standard curve of sodium nitrite $\left(\mathrm{NaNO}_{2}\right)$. In addition, the $\mathrm{PGE}_{2}$ concentration was measured by a $\mathrm{PGE}_{2}$ assay kit according to the manufacturer's instructions (R\&D Systems, Inc., Minneapolis, MN, USA).

Animal experiments. Eight-week-old male apoE ${ }^{-/-}$mice were used in the present study. All animals were obtained from the Jackson Laboratory (Bar Harbor, ME, USA) and maintained at the Korea Research Institute of Bioscience and Biotechnology (KRIBB; Daejeon, Korea) and housed in a controlled temperature $\left(22 \pm 1^{\circ} \mathrm{C}\right)$ facility and maintained on a reverse $12 \mathrm{~h} \mathrm{light} / \mathrm{dark}$ cycle. The mice were randomly divided into three groups: those fed i) an atherogenic diet (no. 102571; Dyets Inc., Bethlehem, PA, USA) plus vehicle (0.5\% CMC) as the vehicle/control group $(\mathrm{n}=9)$; ii) an atherogenic diet plus $100 \mathrm{mg} / \mathrm{kg}$ of $\mathrm{HJ}$ as the $\mathrm{HJ} 100$ group ( $\mathrm{n}=5)$; and iii) an atherogenic diet plus $500 \mathrm{mg} / \mathrm{kg}$ of $\mathrm{HJ}$ as the HJ500 group $(n=8)$. The doses of HJ were determined by preliminary tests using concentrations of 100,300 , and $500 \mathrm{mg} / \mathrm{kg}$ for selection of anti-atherogenic effect. HJ was administered daily by oral gavage for 12 weeks and changes in body weight were measured each week. All animal experiments were approved by the Institutional Animal Care and Use Committee (IACUC) of KRIBB and were performed in accordance with the institutional guidelines at KRIBB.

Plasma analysis. At the end of the experimental period, blood samples were collected from the orbital venous sinuses of the mice to analyze the concentrations of plasma lipid as well as various biomarkers. Plasma was prepared by centrifuging the blood at $10,000 \mathrm{xg}$ for $5 \mathrm{~min}$ at $4^{\circ} \mathrm{C}$ and subsequently storing it at $-70^{\circ} \mathrm{C}$ until analysis. Plasma total cholesterol and triglyceride levels were analyzed using a kit (Asan Pharm, Seoul, Korea), and other biomarkers including aspartate transaminase (AST), alanine transaminase (ALT), blood urea nitrogen (BUN), creatinine (Crea), glucose (Glu), and non-esterified fatty acid (NEFA) were measured using an automatic blood chemical analyzer (Hitachi, Tokyo, Japan).

Analysis of atherosclerotic lesion formation in the aorta of apoE ${ }^{-/-}$mice. The mice were euthanized with $\mathrm{CO}_{2}$ gas, and then the whole aortas were isolated from the vehicle group $(n=4)$, the HJ100 group (n=3), and the HJ500 group $(n=4)$, and the adventitial tissue was removed. After fixation in $10 \%$ neutral formalin, the whole aortas were longitudinally dissected, and pinned flat on a rubber plate. Lipid plaques in the whole aorta were stained with oil-red O (Sigma-Aldrich), and en face images were captured using a digital camera (Canon, Tokyo, Japan). The whole aorta surface and stained plaque areas were analyzed by digital image analysis software (Image Inside; GS Media, Daejeon, Korea).

Analysis of atherosclerotic lesion formation in the aortic sinus of apo $E^{-/-}$mice. The aortic sinuses were isolated from the vehicle group $(n=8)$, the HJ100 group $(n=4)$, and the HJ500 group $(n=7)$, and fixed in $10 \%$ neutral formalin. After fixation, the aortic sinuses were embedded in a Tissue-Tek optimal cutting temperature (OCT) compound and sectioned at a thickness of $8 \mu \mathrm{m}$ using a cryotome (both from Sakura Finetek, Tokyo, Japan). Cryostat sections of the aortic sinus were stained with oil-red O. After oil-red O staining, photographs were captured under a light microscope (BX51; Olympus Corp, Tokyo, Japan) and the atheroma areas of the aortic sinus were quantified using digital image analysis software (Image Inside).

Analysis of monocyte/macrophage infiltration in the aortic sinus of apoE $E^{-/}$mice. The infiltration of monocytes and macrophages was detected using anti-MOMA-2, a mouse monocyte/macrophage-specific antibody (Abcam, Cambridge, UK). The aortic sinuses were embedded in a Tissue-Tek OCT compound, and then sections of the aortic sinus $(8 \mu \mathrm{m})$ were incubated with anti-MOMA-2 (1:200), followed by Alexa Fluor $488 \mathrm{~nm}$ goat anti-rat IgG (1:250) (Invitrogen, Carlsbad, CA, USA) for visualization. Images of the aortic sinus were captured under a dual fluorescence microscope (Carl Zeiss, Oberkochen, Germany). The positively stained areas in the aortic sinus were quantified using digital image analysis software (Image Inside). 

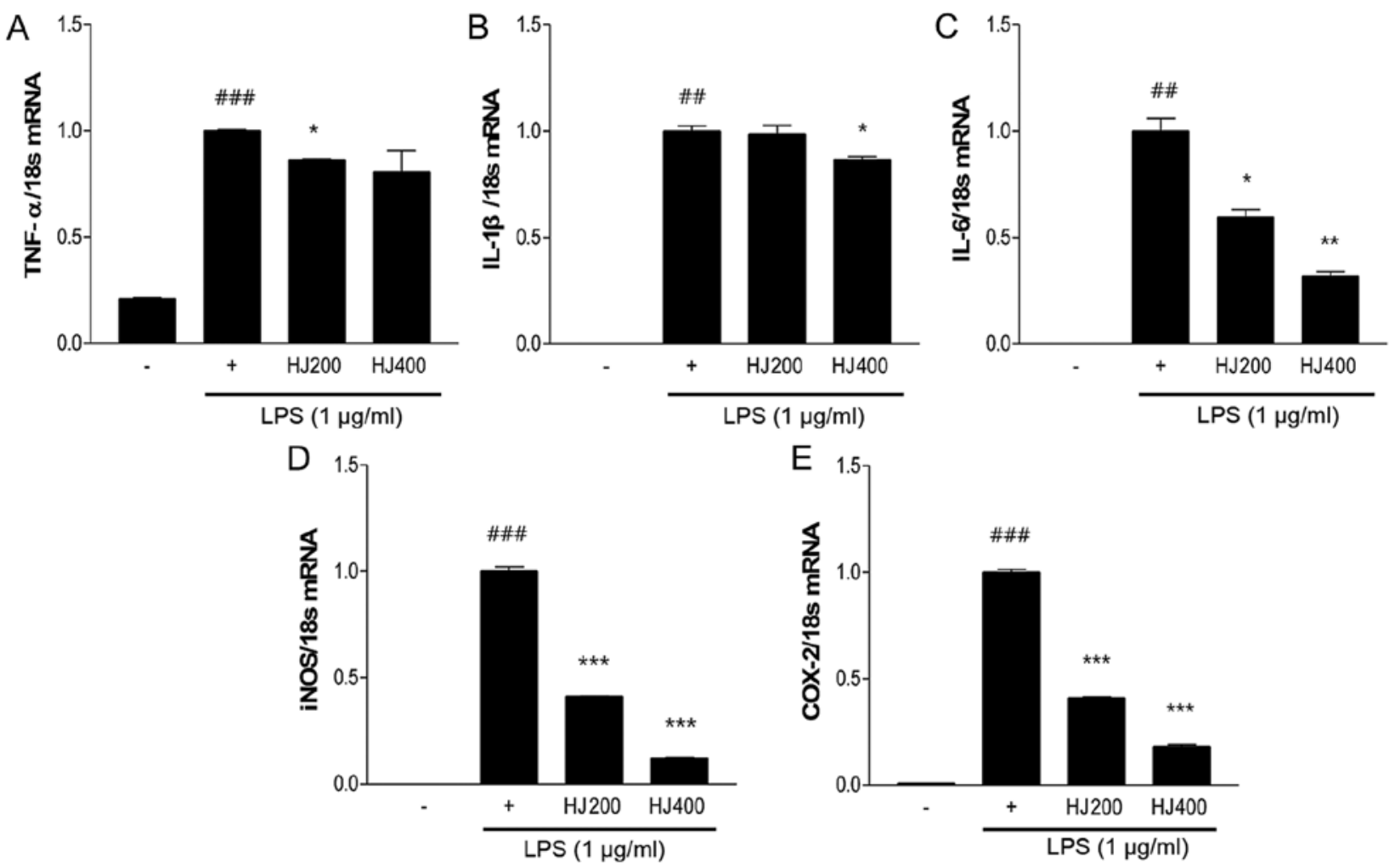

Figure 1. Effect of $H$. japonicus (HJ) on the mRNA expression of pro-inflammatory cytokines and inflammatory mediators in lipopolysaccharide (LPS)-stimulated RAW 264.7 cells. The mRNA expression of (A) tumor necrosis factor- $\alpha$ (TNF- $\alpha$ ), (B) interleukin (IL)-1 $\beta$, (C) IL-6, (D) inducible nitric oxide synthase (iNOS) and (E) cyclooxygenase-2 (COX-2) as measured by RT-qPCR, after normalization of pro-atherogenic gene mRNA signals to 18s mRNA signal for each group. The values are presented as the means \pm SEM of four independent experiments. - group: non-treated cells; + group, LPS-only treated cells; HJ200 and 400 groups, LPS + HJ-treated cells (HJ200 and $400 \mu \mathrm{g} / \mathrm{ml})$. Statistical significance between - and + group, ${ }^{\# \#} \mathrm{P}<0.01$ and ${ }^{\# \# \#} \mathrm{P}<0.001 ;$ statistical significance relative to + group, ${ }^{*} \mathrm{P}<0.05,{ }^{* *} \mathrm{P}<0.01$ and ${ }^{* * *} \mathrm{P}<0.001$.

Assessment of the aortic expression of atherogenic genes in apoE $E^{-/}$mice. Total RNA from the whole aorta in each group was extracted using TRIzol reagent (Invitrogen) according to the manufacturer's instructions, quantified by a NanoDrop ND-1000 spectrophotometer (NanoDrop Technologies, San Diego, CA, USA), and stored at $-70^{\circ} \mathrm{C}$ until analysis. Relative quantification of the gene expression was performed using an Exicycler 96 Real-Time PCR System (Bioneer) with SYBR-Green dye (Takara). Oligonucleotide primers (VCAM-1, ICAM-1, iNOS, COX-2, MCP-1, CD68, IL-1 IL-6 and IL-18) were designed by Primer Express 3.0 software (Applied Biosystems), and the primer sequences used in the experiments are listed in Table I. The cycling conditions were $95^{\circ} \mathrm{C}$ for $10 \mathrm{~min}$, followed by 40 cycles of $95^{\circ} \mathrm{C}$ for $10 \mathrm{sec}$, and $60^{\circ} \mathrm{C}$ for $1 \mathrm{~min}$. To detect and remove possible primer-dimer artifacts, a dissociation curve was generated by adding a cycle of $95^{\circ} \mathrm{C}$ for $15 \mathrm{sec}, 60^{\circ} \mathrm{C}$ for $1 \mathrm{~min}$, and $95^{\circ} \mathrm{C}$ for $15 \mathrm{sec}$. The results were normalized to 18s RNA levels (reference gene).

Statistical analysis. All data are presented as the means \pm standard error of the mean (SEM). For two-group comparisons, a Student's t-test was used. A P-value of $<0.05$ was considered to indicate a statistically significant difference.

\section{Results}

$H J$ inhibits the $M R N A$ expression of inflammation-related genes in LPS-stimulated RAW 264.7 cells. To examine the anti-inflammatory effect of $\mathrm{HJ}$, the mRNA expression of inflammation-related genes (TNF- $\alpha$, IL-1 $\beta$, IL- 6, COX- 2 and iNOS) was measured in HJ-treated RAW 264.7 cells stimulated with LPS. LPS stimulation significantly induced the increased expression of pro-inflammatory genes compared with the non-treated cells. The mRNA expression of TNF- $\alpha$ and IL-1 $\beta$ was significantly decreased in the HJ-treated cells (Fig. 1A and B). In addition, IL-6 mRNA expression was markedly reduced in the $\mathrm{HJ}$-treated groups, particularly in the HJ400 group (by 68\%) compared with IL-6 mRNA expression in the cells treated with LPS only (Fig. 1C). The expression of other inflammatory mediators, such as iNOS and COX-2, markedly decreased after HJ treatment in a dose-dependent manner. Particularly, the mRNA expression of these two genes decreased by $>80 \%$ in the HJ400 group compared with that in the cells treated with LPS only (Fig. 1D and E).

HJ suppresses the secretion of pro-inflammatory cytokines and production of nitrite and $P G E_{2}$ in LPS-stimulated $R A W 264.7$ cells. In addition to assessing the mRNA expression of pro-inflammatory cytokines and inflammatory mediators, we measured the secretion levels of TNF- $\alpha$, IL-1 $\beta$, IL-6, nitrite and $\mathrm{PGE}_{2}$ in the LPS-stimulated RAW 264.7 cells following HJ treatment. As expected, the TNF- $\alpha$ and IL-6 secretion levels were significantly decreased by HJ treatment (Fig. 2A and C). Particularly the HJ400 group showed a $>50 \%$ decrease compared with the cells treated with LPS 

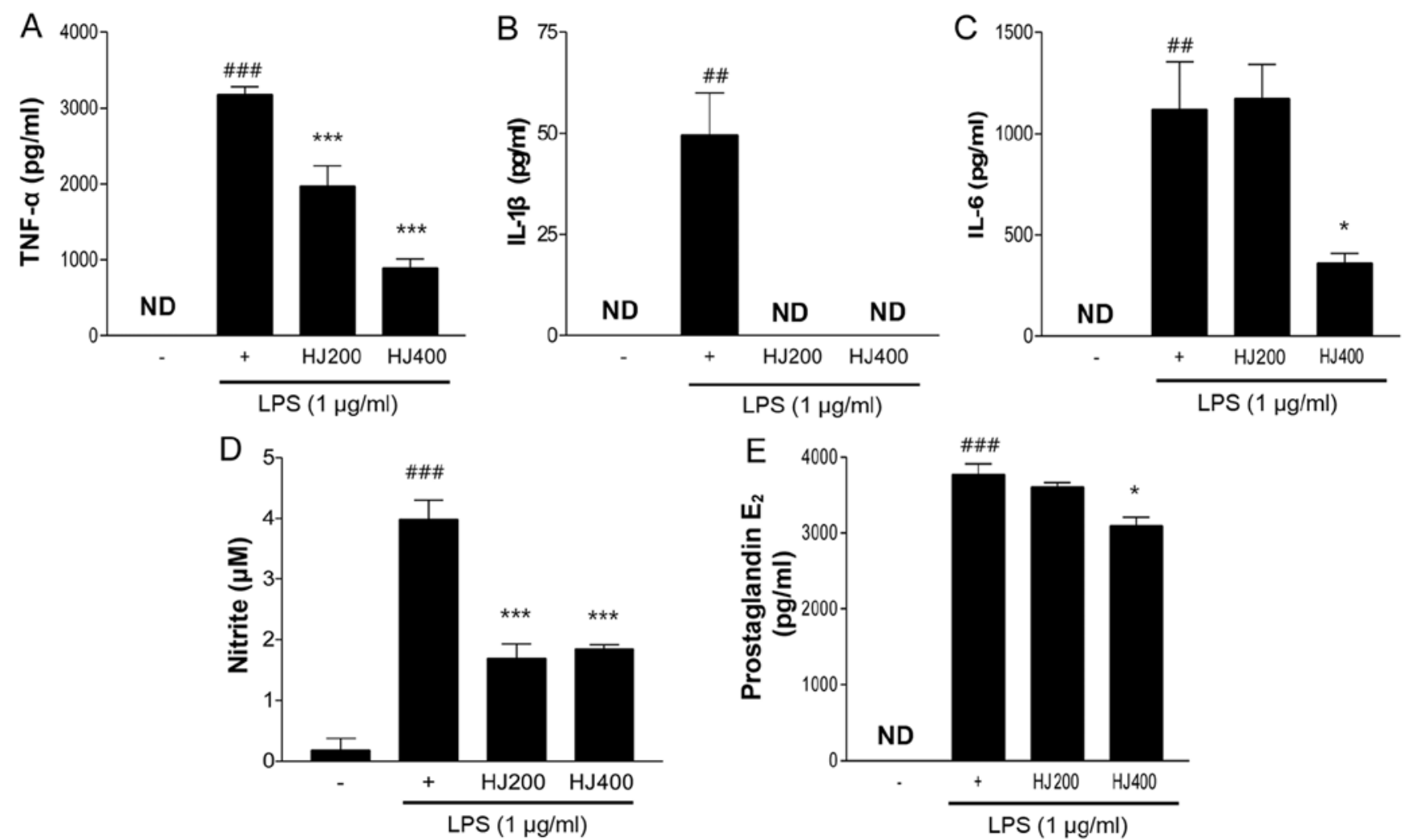

Figure 2. Effect of $H$.japonicus $(\mathrm{HJ})$ on the secretion of pro-inflammatory cytokines as well as the production of nitrite and prostaglandin $\mathrm{E}_{2}\left(\mathrm{PGE}_{2}\right)$ in lipopolysaccharide (LPS)-stimulated RAW 264.7 cells. The secretion levels of (A) tumor necrosis factor- $\alpha$ (TNF- $\alpha$ ), (B) interleukin (IL)-1 $\beta$ and (C) IL-6 as measured by a

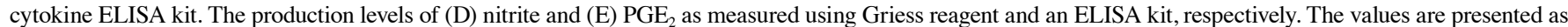
the means \pm SEM of four independent experiments; - group, non-treated cells; + group, LPS-only treated cells; HJ200 and 400 groups, LPS + HJ-treated cells (HJ 200 and $400 \mu \mathrm{g} / \mathrm{ml})$. Statistical significance between - and + group, \#\#P<0.01, ${ }^{\# \# \#} \mathrm{P}<0.001 ;$ statistical significance relative to + group, ${ }^{*} \mathrm{P}<0.05$ and ${ }^{* * *} \mathrm{P}<0.001$.

only. Notably, IL-1 $\beta$ secretion was completely inhibited by HJ treatment regardless of the concentration (Fig. 2B). In general, the increased expression of iNOS leads to the production of high quantities of nitrite, nitrate and superoxide $\left(\mathrm{O}_{2}^{-}\right)(22)$. The release of nitrite in $\mathrm{HJ}$-treated cells was markedly reduced by $>50 \%$ compared with the level of nitrite release in the cells treated with LPS only (Fig. 2D). The effects of $\mathrm{PGE}_{2}$, an inflammatory mediator, are mediated through the induction of COX-2 expression resulting in inflammation (23). The treatment of LPS-stimulated RAW 264.7 cells with $400 \mu \mathrm{g} / \mathrm{ml}$ of $\mathrm{HJ}$ significantly reduced $\mathrm{PGE}_{2}$ levels by $12 \%$ compared with the $\mathrm{PGE}_{2}$ levels in the LPS-only treated cells (Fig. 2E). Taken together, these findings suggest that $\mathrm{HJ}$ inhibits the secretion of pro-inflammatory cytokines and inflammatory mediators in the LPS-stimulated RAW 264.7 cells.

HJ reduces the formation of atherosclerotic lesions in the aortic sinus and the aorta of apoE ${ }^{-/}$mice. To examine the effect of $\mathrm{HJ}$ on the formation of atherosclerotic lesions in vivo, HJ was administered to apoE $E^{-/-}$mice for 12 weeks, and the whole aorta was obtained, stained with oil-red $\mathrm{O}$, and analyzed. No significant change in the number of atherosclerotic lesions in the aortic en face images of the HJ100 group was observed, whereas the number of aortic lesions was markedly reduced in the HJ500 group $(72.09 \pm 14.16 \%)$, compared with the number of lesions in the vehicle group (Fig. 3). Furthermore, the number of atherosclerotic lesions in the aortic sinus was compared following oil-red $\mathrm{O}$ staining. The atherosclerotic area was significantly and dose-dependently decreased in the HJ treatment groups (HJ100 group, 89.71 +4.75\%; HJ500 group, $83.87 \pm 3.97 \%$ ), compared with that in the vehicle group (Fig. 4). These results indicate that high-dose treatment with HJ clearly reduces the formation of atherosclerotic lesions.

HJ inhibits monocyte/macrophage infiltration in the aortic sinus of apoE ${ }^{-/-}$mice. To examine the infiltration of monocytes and macrophages in the arterial intima, we performed immunofluorescence staining for MOMA-2 in the aortic sinus (Fig. 5A). HJ decreased the levels of MOMA-2-positive areas in a dose-dependent manner. Moreover, the areas of the aortic sinus stained by MOMA-2 were quantified using image analysis software, and a significantly decreased monocyte/macrophage infiltration was observed in the HJ-treated mice, compared with that in the control apoE $\mathrm{E}^{-/}$group (Fig. 5B). This finding suggests that $\mathrm{HJ}$ treatment strongly inhibits the infiltration of monocytes and macrophages in the aortic sinus.

$H J$ reduces aortic atherogenic gene expression in apo $E^{-/-}$mice. To further examine the aortic expression of atherogenic genes in $\mathrm{HJ}$-treated apoE ${ }^{-/-}$mice, we measured the mRNA levels of adhesion molecules (VCAM-1 and ICAM-1), inflammatory mediators (iNOS and COX-2), the monocyte/macrophage marker, CD68, and MCP-1, as well as the pro-inflammatory cytokines (IL-1 $\beta$, IL-6 and IL-18) in the HJ500 and the control groups. Among the analyzed parameters, the mRNA expression of ICAM-1, MCP-1, CD68 and IL-18 was significantly 

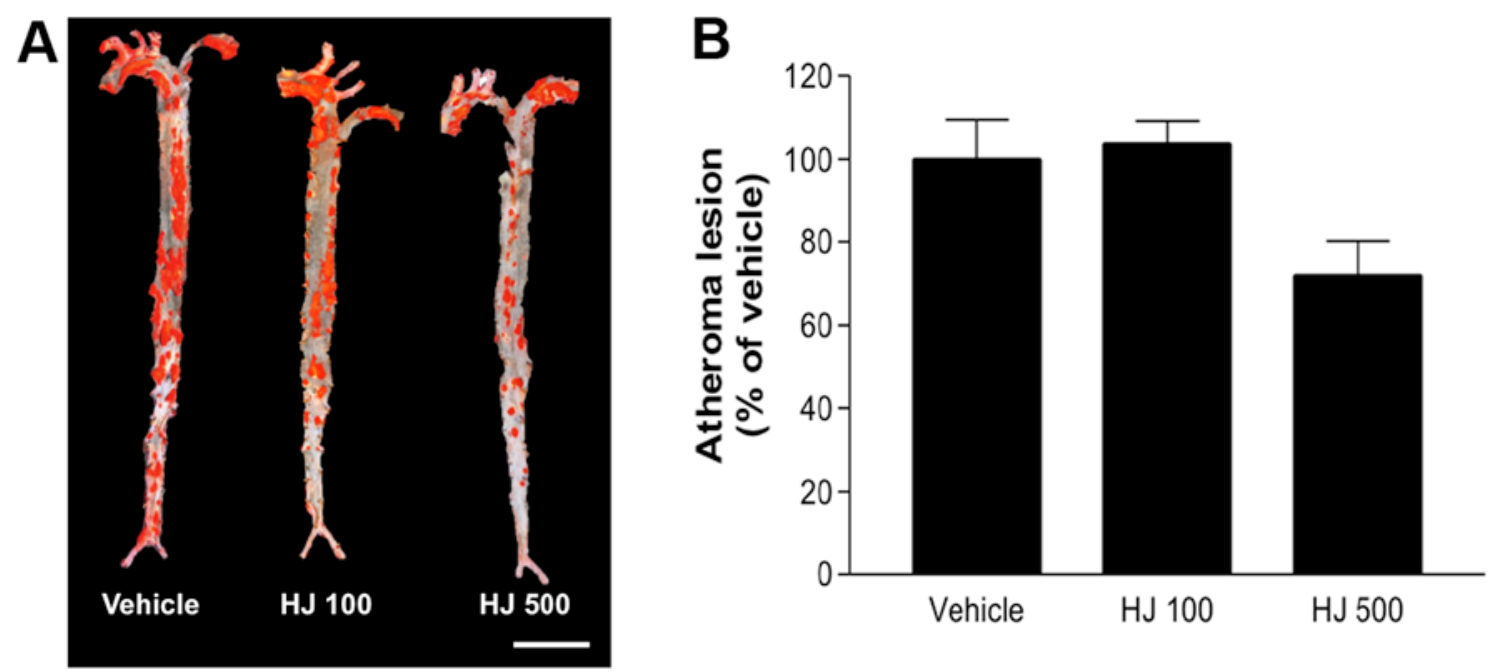

Figure 3. Effect of H. japonicus (HJ) on the development of atherosclerotic lesions in the aorta of apolipoprotein E-deficient $\left(\mathrm{apoE}^{-/}\right) \mathrm{mice}^{-}$The apoE $\mathrm{E}^{-/} \mathrm{mice}$ were fed an atherogenic diet plus either vehicle [0.5\% carboxymethyl cellulose (CMC); vehicle group], or 100 or $500 \mathrm{mg} / \mathrm{kg}$ of $\mathrm{HJ}$ (HJ100 and 500 groups) for 12 weeks. (A) The whole aorta of apoE ${ }^{-/}$mice in each group stained with oil-red O. Scale bar, $500 \mu \mathrm{m}$ (B) Quantification of the oil-red O positive areas in the whole aorta of apoE $\mathrm{E}^{-/}$mice using image analysis software. The values are presented as the means \pm SEM.

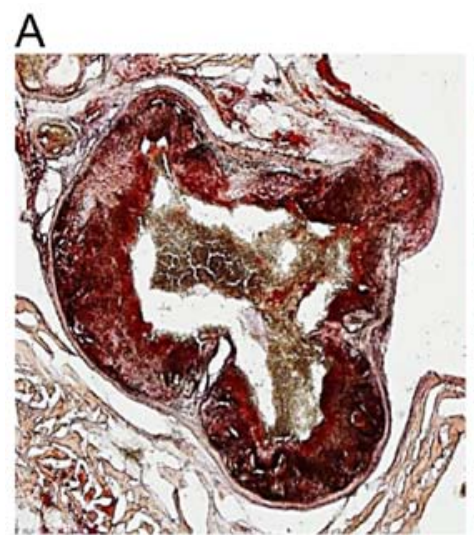

Vehicle

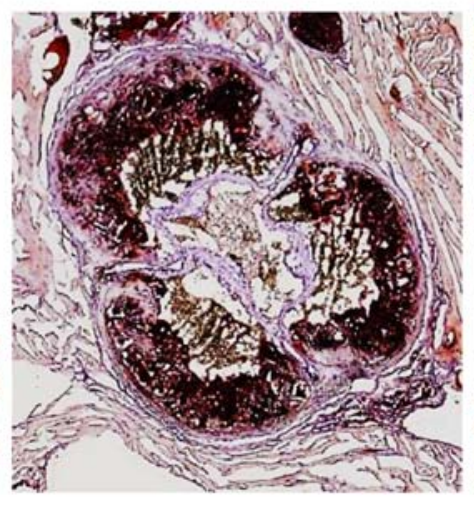

HJ100

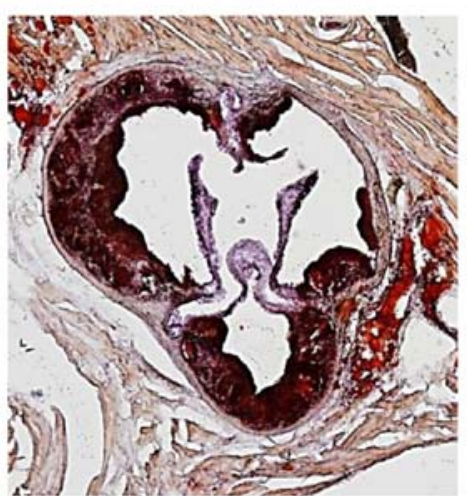

HJ500

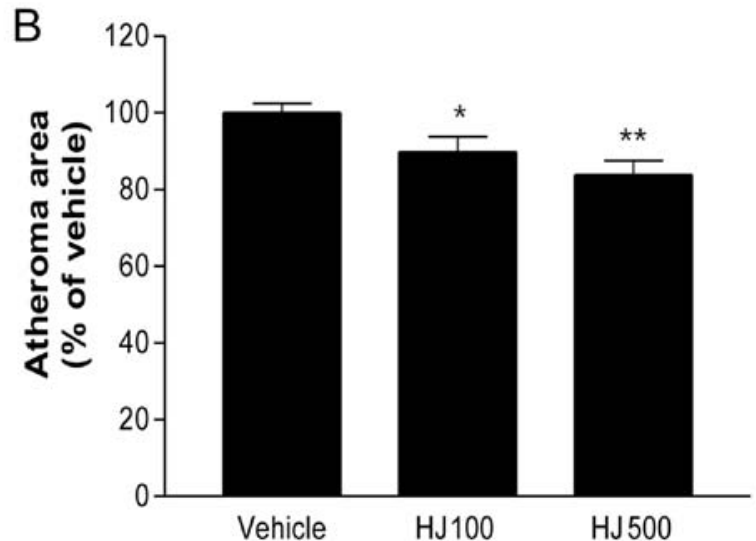

Figure 4. Effect of $H$. japonicus (HJ) on the formation of atherosclerotic plaques in the aortic sinus in apolipoprotein E-deficient $\left(\right.$ apoE $\left.{ }^{-/}\right) \mathrm{mice}$. The apoE ${ }^{-/-} \mathrm{mice}$ were fed either an atherogenic diet plus vehicle [0.5\% carboxymethyl cellulose (CMC); vehicle group], or 100 or $500 \mathrm{mg} / \mathrm{kg}$ of $\mathrm{HJ}$ (HJ100 and 500 groups) for 12 weeks. (A) The aortic sinus of apoE ${ }^{-/}$mice in each group stained with oil-red $\mathrm{O}(\mathrm{x} 40)$. (B) Quantification of the atherosclerotic plaque areas in the aortic sinus of apoE ${ }^{-/}$mice using image analysis software. The values are presented as the means \pm SEM. Statistical significance relative to vehicle group, ${ }^{*} \mathrm{P}<0.05$ and ${ }^{* * *} \mathrm{P}<0.01$.

decreased in the HJ500 group compared with that in the control group (Fig. 6). These results indicate that HJ may reduce the expression of the pro-inflammatory cytokines and atherogenic genes, thereby regulating the migration and the infiltration of mainly monocytes/macrophages, in the aorta of HJ-treated $\mathrm{apoE}^{-/ /}$mice. 


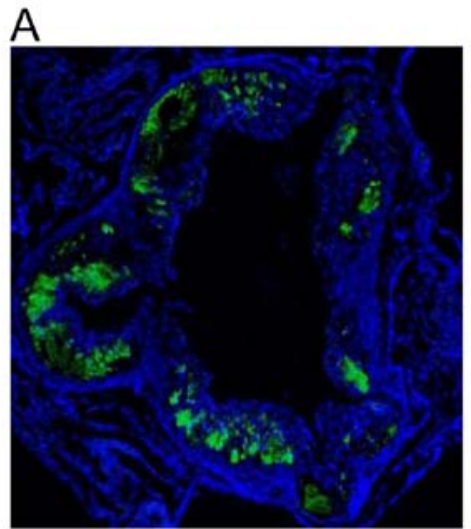

Vehicle

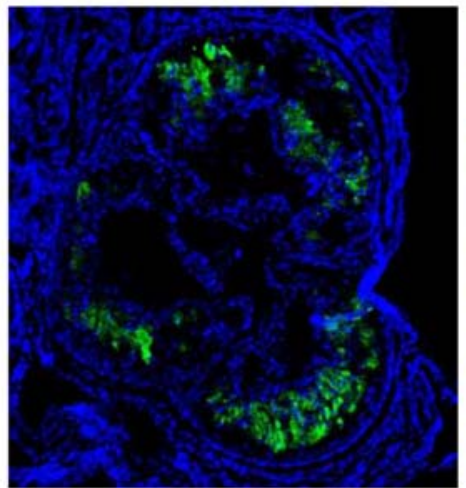

HJ100

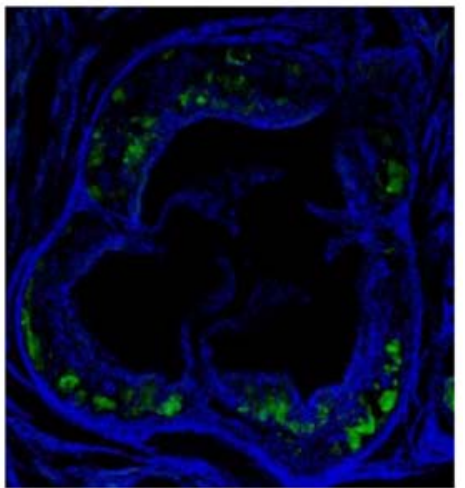

HJ500

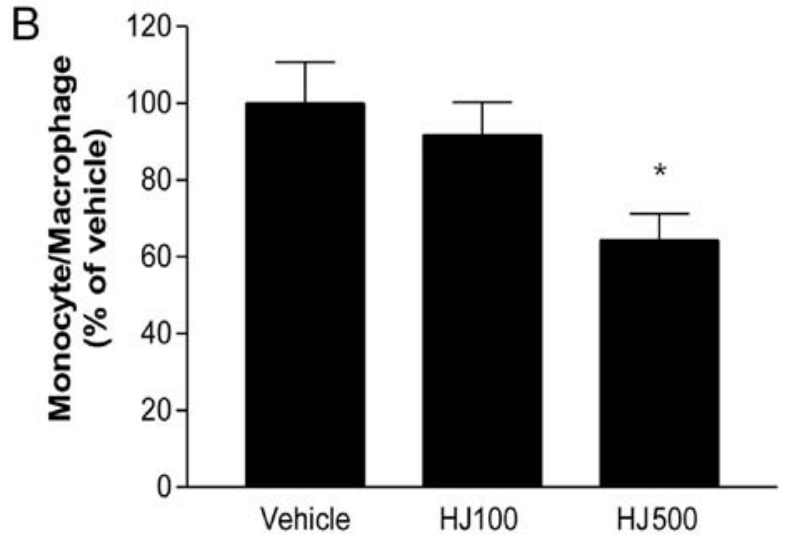

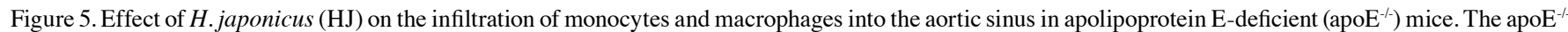
mice were fed an atherogenic diet plus either vehicle [0.5\% carboxymethyl cellulose (CMC); vehicle group], or $100 \mathrm{or} 500 \mathrm{mg} / \mathrm{kg}$ of $\mathrm{HJ}$ (HJ100 and $500 \mathrm{groups}$ ) for 12 weeks. (A) The aortic sinus stained with MOMA2 antibody (monocyte+macrophage, green) and DAPI (nucleus, blue); x50 magnification. (B) Quantification of the MOMA-2 positive areas in the aortic sinus of apoE ${ }^{-/}$mice using image analysis software. The values are presented as the means \pm SEM. Statistical significance relative to vehicle group, ${ }^{*} \mathrm{P}<0.05$.
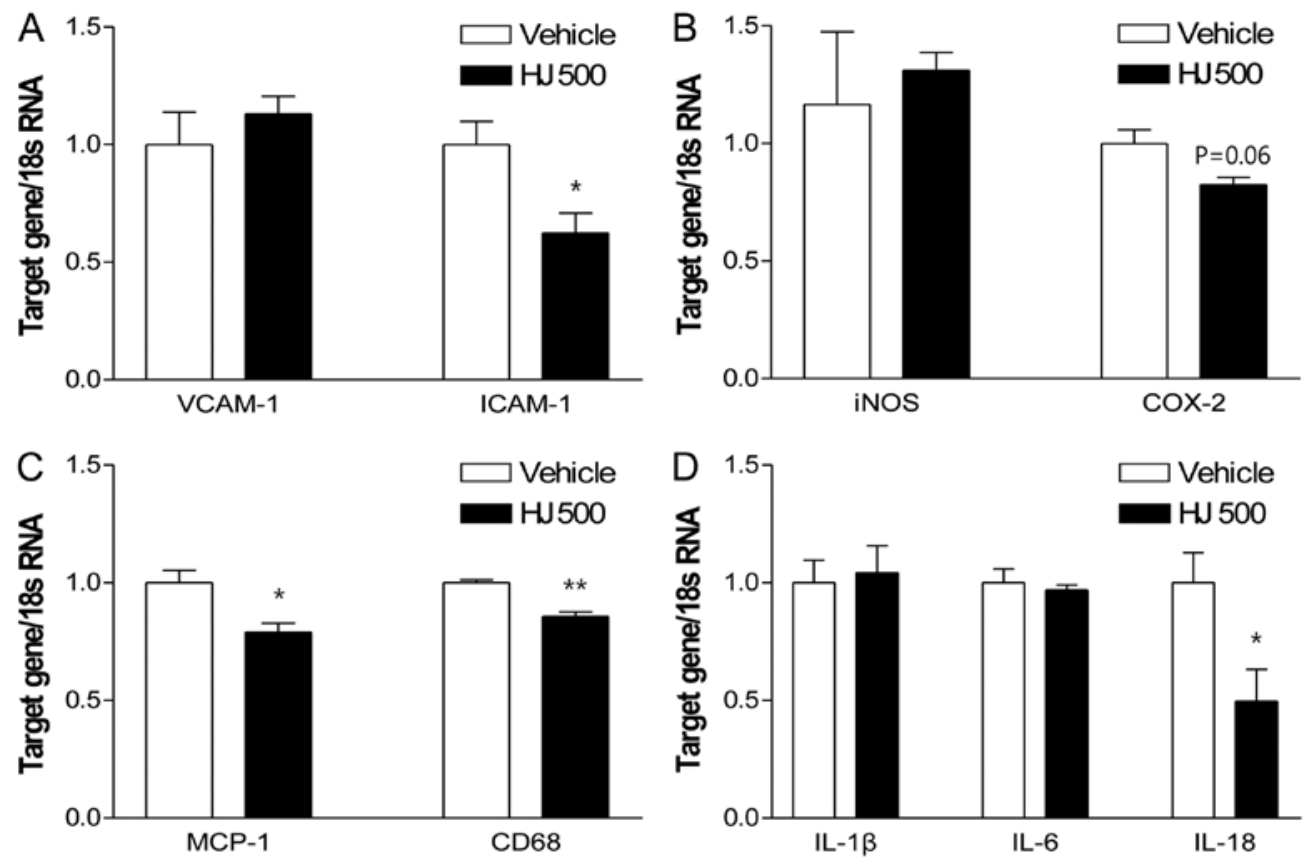

Figure 6. Effect of H.japonicus $(\mathrm{HJ})$ on pro-atherogenic gene expression in the aorta of apolipoprotein $\mathrm{E}_{-\mathrm{deficient}}\left(\mathrm{apoE} \mathrm{E}^{-/}\right) \mathrm{mice}^{-} \mathrm{The}^{\mathrm{apoE}} \mathrm{E}^{-/}$mice were fed an atherogenic diet plus either vehicle [0.5\% carboxymethyl cellulose (CMC)] as the vehicle group (unfilled bar), and $500 \mathrm{mg} / \mathrm{kg}$ of $\mathrm{HJ}$ as the HJ500 group (filled bar) for 12 weeks. The whole aortas from 3-4 mice in each group were pooled to extract RNA. The mRNA expression of (A) vascular cell adhesion molecule-1 (VCAM-1) and intercellular adhesion molecule-1 (ICAM-1), (B) inducible nitric oxide synthase (iNOS) and cyclooxygenase 2 (COX-2), (C) monocyte chemoattractant protein-1 (MCP-1) and CD68, and (D) interleukin (IL)-1 $\beta$, IL-6, and IL-18 as measured by RT-qPCR and normalized by 18s mRNA signal. The values are presented as the means \pm SEM. Statistical significance relative to vehicle group, ${ }^{*} \mathrm{P}<0.05$ and ${ }^{* *} \mathrm{P}<0.01$. 
Table II. Effects of HJ on plasma biomarkers in apoE ${ }^{-/-}$mice.

\begin{tabular}{|c|c|c|c|c|c|c|c|c|}
\hline Groups & $\begin{array}{c}\text { AST } \\
(\mathrm{IU} / \mathrm{l})\end{array}$ & $\begin{array}{l}\text { ALT } \\
(\mathrm{IU} / \mathrm{l})\end{array}$ & $\begin{array}{c}\text { BUN } \\
(\mathrm{mg} / \mathrm{dl})\end{array}$ & $\begin{array}{c}\text { Crea } \\
(\mathrm{mg} / \mathrm{dl})\end{array}$ & $\begin{array}{c}\text { Glu } \\
(\mathrm{mg} / \mathrm{dl})\end{array}$ & $\begin{array}{c}\text { NEFA } \\
(\mathrm{mEq} / \mathrm{l})\end{array}$ & $\begin{array}{c}\mathrm{TG} \\
(\mathrm{mg} / \mathrm{dl})\end{array}$ & $\begin{array}{c}\mathrm{TC} \\
(\mathrm{mg} / \mathrm{dl})\end{array}$ \\
\hline Vehicle & $96.1 \pm 4.8$ & $35.3 \pm 2.6$ & $35.0 \pm 9.0$ & $0.3 \pm 0.0$ & $112.5 \pm 4.9$ & $1.6 \pm 0.1$ & $179.5 \pm 12.0$ & $1485.8 \pm 54.8$ \\
\hline HJ100 & $112.2 \pm 26.8$ & $31.2 \pm 3.7$ & $28.8 \pm 1.9$ & $0.3 \pm 0.0$ & $136.3 \pm 14.3$ & $1.2 \pm 0.1$ & $157.7 \pm 21.4$ & $1504.4 \pm 30.2$ \\
\hline HJ500 & $96.2 \pm 6.4$ & $32.8 \pm 2.2$ & $26.1 \pm 1.4$ & $0.2 \pm 0.0$ & $115.9 \pm 6.7$ & $1.9 \pm 0.1$ & $139.6 \pm 8.7^{\mathrm{a}}$ & $1541.0 \pm 23.0$ \\
\hline
\end{tabular}

The values are presented as the means $\pm \mathrm{SEM}$. Statistical significance relative to the vehicle group, ${ }^{\mathrm{a}} \mathrm{P}<0.05$. $\mathrm{HJ}$, H. japonicus; apoE ${ }^{---}$, apolipoprotein E-deficient, AST, aspartate transaminase; ALT, alanine transaminase; BUN, blood urea nitrogen; Crea, creatinine; Glu, glucose; NEFA, non-esterified fatty acid; TG, triglyceride; TC, total cholesterol.

Plasma analysis. Plasma lipid and other physiological biomarkers were also determined in the HJ- or vehicle-treated apoE $^{-/-}$mice. Apart from a decrease in plasma triglyceride levels in both the HJ100 and the HJ500 groups compared with the control group, no significant changes were found in cholesterol, NEFA, AST, ALT, BUN, Crea and Glu levels (Table II). Moreover, the changes in body weight were not significantly different among groups during the whole period of the experiments (data not shown). Based on these results, it is suggested that long-term treatment with $\mathrm{HJ}$, at least for 12 weeks in apoE ${ }^{-/-}$mice, does not induce significant toxic effects.

\section{Discussion}

The present study showed that HJ effectively inhibits atherogenesis by suppressing inflammation and the development of atherosclerotic lesions in LPS-stimulated RAW 264.7 cells and apoE $^{-/-}$mice, respectively. Inflammation caused by inflammatory cytokines and chemokines is the response of tissue to injury (24). LPS is one of the most well-known macrophage-activating factors, and is usually used for evaluating anti-inflammatory effects (25). In addition, LPS stimulates the production of various inflammatory cytokines and mediators such as nitric oxide (NO), TNF- $\alpha$, and ILs, thereby affecting the immune response $(26,27)$. To determine whether HJ exerts an anti-inflammatory effect, we measured the gene expression of pro-inflammatory cytokines and mediators, and their secretion levels in LPS-stimulated RAW 264.7 cells. Pro-inflammatory cytokines (TNF- $\alpha$, IL-1 $\beta$ and IL-6) play crucial roles in the initiation of inflammatory processes including immune cell recruitment, thereby promoting the formation of atherosclerotic lesions (28). Moreover, iNOS and COX-2 are crucial mediators of inflammation. iNOS catalyzes the oxidative deamination of L-arginine to produce NO, a highly reactive free radical involved in several physiological and pathological processes $(29,30)$. The modulation of iNOS-mediated NO release is a major step in the inflammatory process (31). COX-2, an inducible isoform of COX, plays an important role in inflammation and produces $\mathrm{PGE}_{2}$, also involved in inflammation (32). In this study, HJ demonstrated a potent anti-inflammatory effect by suppressing the expression of pro-inflammatory cytokines and mediators, and their secretion in LPS-stimulated RAW 264.7 cells. These findings suggest that the anti-inflammatory activity of HJ may contribute to its anti-atherosclerotic effect.
In order to observe the effect of HJ on the development of atherosclerotic lesions, the lesions in the whole aorta and aortic sinus of apoE ${ }^{-/-}$mice were analyzed after staining with oil-red $\mathrm{O}$. Indeed, $\mathrm{HJ}$ treatment for 12 weeks markedly reduced lesion formation in both the aorta (en face) and the aortic sinus in apoE $\mathrm{E}^{-/-}$mice fed an atherogenic diet, particularly in the HJ500 group. It is well known that macrophages produce a variety of cytokines and tissue factors in atherosclerotic lesions. Thus, the inhibitory effect of HJ on monocyte and macrophage infiltration was investigated in the aortic sinus of apoE $\mathrm{E}^{-/-}$mice fed an atherogenic diet by immunofluorescent staining with MOMA-2 . Quantitative analysis showed that the degree of infiltration was significantly reduced in the HJ500 group compared with the degree of infiltration in the vehicle group. These histological findings indicate that $\mathrm{HJ}$ exerts an anti-atherogenic effect and may potentially be used as a novel natural compound for inhibiting the development of atherosclerosis.

Previously, it was reported that atherosclerotic lesions form and develop as a consequence of lipid uptake as well as monocyte recruitment in arterial intima, and subsequent transformation into macrophage foam cells (4). During this process, activated arterial endothelial cells express various leukocyte adhesion molecules and chemokines which affect the progression of atherogenesis $(33,34)$. The role of adhesion molecules in atherosclerosis has been reported previously $(35,36)$. These studies suggest that the expression of adhesion molecules affects the recruitment of immune cells to the arterial intima. Among them, VCAM-1 and ICAM-1, well-known endothelial adhesion molecules of the Ig gene superfamily, may participate in the pathogenesis of atherosclerosis by promoting monocyte accumulation in the arterial intima. Particularly ICAM-1 has well-established roles in $\mathrm{T}$ cell activation and in interactions between leukocytes and endothelial cells $(37,38)$. MCP-1, a member of the cysteine-cysteine chemokine family, is responsible for both lipid accumulation and monocyte recruitment into the arterial walls which affects the progression of atherosclerosis (39). Previously, studies have reported that the absence of MCP-1 or the inhibition of adhesion molecule expression ameliorates atherosclerosis in various models of atherosclerosis, including apoE ${ }^{-/}$mice (40), LDL receptor-deficient mice (41), and double-knockout (apoE ${ }^{-/ /} / \mathrm{ICAM}^{-1 /-}$ ) mice (42). Moreover, CD68, a pan-macrophage marker, is involved in the inflammation of carotid plaques. It contributes to the formation of a fibrous cap and negatively correlates with plaque cap thickness (43-45). IL-18, a member of the 
IL-1 family of cytokines, has been widely studied in inflammatory diseases including atherosclerosis (46-48). It was highly expressed in atherosclerotic plaques compared with the normal and control human carotid atherosclerotic plaques, and was localized in plaque macrophages (49). Therefore, the downregulation of pro-atherogenic genes may suppress the development of atherosclerotic lesions. In the present study, the expression of pro-atherogenic genes (ICAM-1, MCP-1, CD68 and IL-18) significantly decreased following HJ treatment in apoE ${ }^{-/}$mice fed an atherogenic diet. These findings suggest that $\mathrm{HJ}$ inhibits atherosclerosis, in part, by downregulating the expression of atherogenic genes, such as adhesion molecules (ICAM-1) and cytokines, leading to a reduction in vascular inflammation, and in monocyte and neutrophil recruitment.

To the best of our knowledge, this is the first study to report that HJ suppresses the development of atherosclerosis by inhibiting the expression of pro-atherogenic factors, such as pro-inflammatory cytokines, chemokines and adhesion molecules, which is followed by the prevention of lipid accumulation in the aortic endothelium in apoE ${ }^{-/-}$mice. In conclusion, HJ may have potential applications as an effective, therapeutically potent natural product for preventing atherosclerosis.

\section{Acknowledgements}

The present study was supported by the KRIBB Research Initiative Program of the Republic of Korea. The authors wish to thank In-Bok Lee, Jung-Hyun Choi, and Yun-Jeong Seo for their technical assistance.

\section{References}

1. World Health Organization: Cardiovascular diseases (CVDs) http://www.who.int/mediacentre/factsheets/fs317/en. Accessed March 12, 2015.

2. Lusis AJ: Atherosclerosis. Nature 407: 233-241, 2000.

3. Rosamond WD, Chambless LE, Folsom AR, Cooper LS, Conwill DE, Clegg L, Wang CH and Heiss G: Trends in the incidence of myocardial infarction and in mortality due to coronary heart disease, 1987 to 1994. N Engl J Med 339: 861-867, 1998.

4. Ross R: Atherosclerosis - an inflammatory disease. N Engl J Med 340: 115-126, 1999.

5. Zernecke A and Weber C: Chemokines in atherosclerosis: proceedings resumed. Arterioscler Thromb Vasc Biol 34: 742-750, 2014

6. Braunwald E: Shattuck lecture - cardiovascular medicine at the turn of the millennium: triumphs, concerns, and opportunities. N Engl J Med 337: 1360-1369, 1997.

7. Breslow JL: Cardiovascular disease burden increases, NIH funding decreases. Nat Med 3: 600-601, 1997.

8. Hansson GK and Libby P: The immune response in atherosclerosis: a double-edged sword. Nat Rev Immunol 6: 508-519, 2006.

9. Wildgruber M, Swirski FK and Zernecke A: Molecular imaging of inflammation in atherosclerosis. Theranostics 3: 865-884, 2013.

10. Stocker R and Keaney JF Jr: Role of oxidative modifications in atherosclerosis. Physiol Rev 84: 1381-1478, 2004.

11. Witztum JL and Steinberg D: Role of oxidized low density lipoprotein in atherogenesis. J Clin Invest 88: 1785-1792, 1991.

12. Janeway CA Jr and Medzhitov R: Innate immune recognition. Annu Rev Immunol 20: 197-216, 2002.

13. Moore KJ, Sheedy FJ and Fisher EA: Macrophages in atherosclerosis: a dynamic balance. Nat Rev Immunol 13: 709-721, 2013.

14. Peiser L, Mukhopadhyay S and Gordon S: Scavenger receptors in innate immunity. Curr Opin Immunol 14: 123-128, 2002.

15. Park JW, Ko SH, Kim CW, Jeoung BJ and Hong CS: Identification and characterization of the major allergen of the Humulus japonicus pollen. Clin Exp Allergy 29: 1080-1086, 1999.
16. Jeong KY, Han IS, Choi SY, Lee JH, Lee JS, Hong CS and Park JW: Allergenicity of recombinant profilins from Japanese hop, Humulus japonicus. J Investig Allergol Clin Immunol 23: 345-350, 2013.

17. Park SW, Chung SK and Kim SH: Antimutagenic effects and isolation of flavonoids from Humulus japonicus extract. Korean Soc Food Sci Technol 27: 879-901, 1995.

18. Park SW, Woo CJ, Chung SK and Chung KT: Antimicrobial and antioxidative activities of solvent fraction from Humulus japonicus. Korean Soc Food Sci Technol 26: 464-470, 2000.

19. Lee YR, Kim KY, Lee SH, Kim MY, Park HJ and Jeong HS: Antioxidant and Antitumor Activities of Methanolic Extract form Humulus japonicus. Korean Soc Food Sci Technol 25: 357-361, 2012.

20. Hong MS, Son ES, Lee SJ, Lee SK, Lee YJ, Song SD, Cho SN, Clifton E and Eum SY: Anti-mycobacterial effects of the extract of Humulus japonicus. Korean Soc Food Sci Technol 46: 94-99, 2014.

21. Hwang SY, Jung HJ, Jang WS, Jo MJ, Kim SC and Jee SY: Antiinflammatory effects of the $\mathrm{MeOH}$ extract of Humulus japonicus in vitro. J Korean Med Ophthalmol Otolaryngol Dermatol 22: 71-79, 2009 (In Korean).

22. Xia Y, Roman LJ, Masters BS and Zweier JL: Inducible nitricoxide synthase generates superoxide from the reductase domain. J Biol Chem 273: 22635-22639, 1998.

23. Surh YJ, Chun KS, Cha HH, Han SS, Keum YS, Park KK and Lee SS: Molecular mechanisms underlying chemopreventive activities of anti-inflammatory phytochemicals: down-regulation of COX-2 and iNOS through suppression of NF-kappa B activation. Mutat Res 480-481: 243-268, 2001.

24. Park CM and Song YS: Luteolin and luteolin-7-O-glucoside inhibit lipopolysaccharide-induced inflammatory responses through modulation of NF- $\mathrm{kB} / \mathrm{AP}-1 / \mathrm{PI} 3 \mathrm{~K}-\mathrm{Akt}$ signaling cascades in RAW 264.7 cells. Nutr Res Pract 7: 423-429, 2013.

25. Chun SC, Jee SY, Lee SG, Park SJ, Lee JR and Kim SC: Anti-inflammatory activity of the methanol extract of moutan cortex in LPS-activated Raw264.7 cells. Evid Based Complement Alternat Med 4: 327-333, 2007.

26. Kubes $P$ and McCafferty DM: Nitric oxide and intestinal inflammation. Am J Med 109: 150-158, 2000.

27. Watson WH, Zhao Y and Chawla RK: S-adenosylmethionine attenuates the lipopolysaccharide-induced expression of the gene for tumour necrosis factor alpha. Biochem J 342: 21-25, 1999.

28. Adams DO and Hamilton TA: The cell biology of macrophage activation. Annu Rev Immunol 2: 283-318, 1984.

29. Moncada S, Palmer RM and Higgs EA: Nitric oxide: physiology, pathophysiology, and pharmacology. Pharmacol Rev 43: 109-142, 1991.

30. Wink DA, Vodovotz Y, Laval J, Laval F, Dewhirst MW and Mitchell JB: The multifaceted roles of nitric oxide in cancer. Carcinogenesis 19: 711-721, 1998.

31. Kim ND, Kim EM, Kang KW, Cho MK, Choi SY and Kim SG: Ginsenoside Rg3 inhibits phenylephrine-induced vascular contraction through induction of nitric oxide synthase. Br J Pharmacol 140: 661-670, 2003.

32. Vane JR, Bakhle YS and Botting RM: Cyclooxygenases 1 and 2. Annu Rev Pharmacol Toxicol 38: 97-120, 1998.

33. Collins RG, Velji R, Guevara NV, Hicks MJ, Chan L and Beaudet AL: P-Selectin or intercellular adhesion molecule (ICAM)-1 deficiency substantially protects against atherosclerosis in apolipoprotein E-deficient mice. J Exp Med 191: 189-194, 2000.

34. Cybulsky MI and Gimbrone MA Jr: Endothelial expression of a mononuclear leukocyte adhesion molecule during atherogenesis. Science 251: 788-791, 1991.

35. Braunersreuther V and Mach F: Leukocyte recruitment in atherosclerosis: potential targets for therapeutic approaches? Cell Mol Life Sci 63: 2079-2088, 2006.

36. Huo Y and Ley K: Adhesion molecules and atherogenesis. Acta Physiol Scand 173: 35-43, 2001.

37. Broide DH, Humber D, Sullivan S and Sriramarao P: Inhibition of eosinophil rolling and recruitment in P-selectin- and intracellular adhesion molecule-1-deficient mice. Blood 91: 2847-2856, 1998.

38. Kuhlman P, Moy VT, Lollo BA and Brian AA: The accessory function of murine intercellular adhesion molecule-1 in $\mathrm{T}$ lymphocyte activation. Contributions of adhesion and co-activation. J Immunol 146: 1773-1782, 1991.

39. Parhami F, Fang ZT, Fogelman AM, Andalibi A, Territo MC and Berliner JA: Minimally modified low density lipoprotein-induced inflammatory responses in endothelial cells are mediated by cyclic adenosine monophosphate. J Clin Invest 92: 471-478, 1993. 
40. Nagarajan S, Burris RL, Stewart BW, Wilkerson JE and Badger TM: Dietary soy protein isolate ameliorates atherosclerotic lesions in apolipoprotein E-deficient mice potentially by inhibiting monocyte chemoattractant protein-1 expression. J Nutr 138: 332-337, 2008.

41. Gu L, Okada Y, Clinton SK, Gerard C, Sukhova GK, Libby P and Rollins BJ: Absence of monocyte chemoattractant protein-1 reduces atherosclerosis in low density lipoprotein receptordeficient mice. Mol Cell 2: 275-281, 1998.

42. Bourdillon MC, Poston RN, Covacho C, Chignier E, Bricca G and McGregor JL: ICAM-1 deficiency reduces atherosclerotic lesions in double-knockout mice (ApoE $\left(\left(^{--}\right) / \operatorname{ICAM}-1\left(^{--}\right)\right.$) fed a fat or a chow diet. Arterioscler Thromb Vasc Biol 20: 2630-2635, 2000.

43. Medbury HJ, James V, Ngo J, Hitos K, Wang Y, Harris DC and Fletcher JP: Differing association of macrophage subsets with atherosclerotic plaque stability. Int Angiol 32: 74-84, 2013.

44. Medbury HJ, Tarran SL, Guiffre AK, Williams MM, Lam TH, Vicaretti M and Fletcher JP: Monocytes contribute to the atherosclerotic cap by transformation into fibrocytes. Int Angiol 27: $114-123,2008$
45. Ren S, Fan X, Peng L, Pan L, Yu C, Tong J, Zhang W and Liu P: Expression of NF-kB, CD68 and CD105 in carotid atherosclerotic plaque. J Thorac Dis 5: 771-776, 2013.

46. Ghayur T, Banerjee S, Hugunin M, Butler D, Herzog L, Carter A, Quintal L, Sekut L, Talanian R, Paskind M, et al: Caspase-1 processes IFN-gamma-inducing factor and regulates LPS-induced IFN-gamma production. Nature 386: 619-623, 1997.

47. Gu Y, Kuida K, Tsutsui H, Ku G, Hsiao K, Fleming MA, Hayashi N, Higashino K, Okamura H, Nakanishi K, et al: Activation of interferon-gamma inducing factor mediated by interleukin-1beta converting enzyme. Science 275: 206-209, 1997.

48. Seta Y, Kanda T, Tanaka T, Arai M, Sekiguchi K, Yokoyama T, Kurimoto M, Tamura J and Kurabayashi M: Interleukin 18 in acute myocardial infarction. Heart 84: 668-669, 2000.

49. Mallat Z, Corbaz A, Scoazec A, Besnard S, Lesèche G, Chvatchko Y and Tedgui A: Expression of interleukin-18 in human atherosclerotic plaques and relation to plaque instability. Circulation 104: 1598-1603, 2001. 